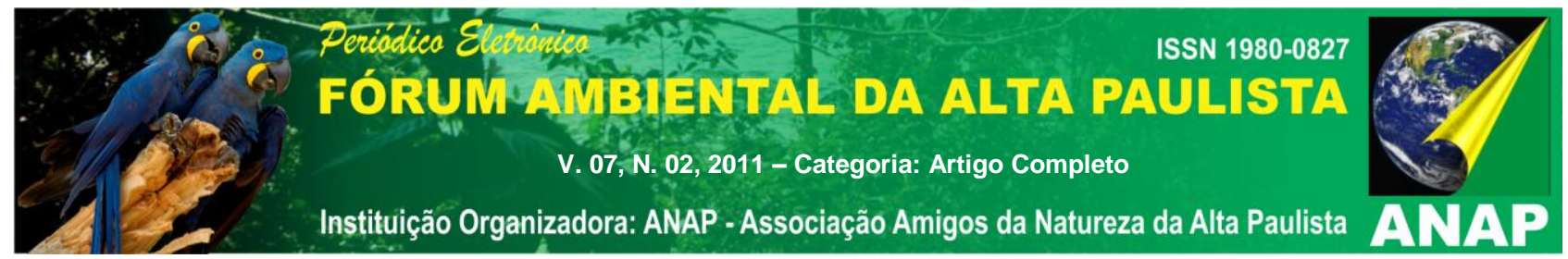

\title{
O PATRIMÔNIO NATURAL GEOLÓGICO COMO UM COMPONENTE DA PAISAGEM FLUVIAL NO MÉDIO TIETÊ-SOROCABA
}

\author{
Fernando Vicente de Oliveira ${ }^{1}$
}

\author{
André Munhoz de Argollo Ferrão
}

RESUMO: O objetivo deste artigo é caracterizar o Patrimônio Natural Geológico como um componente fundamental da paisagem na Bacia Hidrográfica do Sorocaba Médio Tietê (BHSMT), entre as cidades de Cabreúva, Itu, Salto e Porto Feliz, no Estado de São Paulo, Brasil, através de um parque fluvial, a ser apresentado em forma de carta geográfica, assim como de evidenciá-lo através de sua composição pela integração dos parques geológicos existentes na região. Esse patrimônio se comprova de grande relevância, tanto no contexto nacional como internacional entendido como algo a ser preservado, pelo seu valor intrínseco natural e de suas políticas de preservação. Seus espaços físicos são reconhecidos como história da formação do planeta. O parque fluvial a ser apresentado é entendido enquanto uma potencialidade e ferramenta para o uso do planejamento e da ordenação territorial das bacias hidrográficas, pois englobam várias municipalidades. Os parques também levam em conta as representações sociais e culturais, pois seu processo de execução contempla o binômio paisagem e patrimônio. Assim enquanto se promove o desenvolvimento do território, pode-se explorar suas atividades turísticas e culturais.

Palavras chave: Parque fluvial. Bacia Hidrográfica. Patrimônio geológico

\section{BREVE HISTÓRICO SOBRE O CONCEITO DE PATRIMÔNIO}

\footnotetext{
${ }^{1}$ Arquiteto e Urbanista, doutorando pela Universidade Estadual de Campinas/ FEC/ Faculdade de Engenharia Civil, Arquitetura e Urbanismo. Professor do Curso de Arquitetura e Urbanismo, Faculdade Paulista UNIP, unidades de Sorocaba e Alphaville [SP], Brasil. E-mail: $<$ fervioli@bol.com.br>

${ }^{2}$ Professor Livre Docente, Universidade Estadual de Campinas. Doutor em Arquitetura e Urbanismo, Mestre em Engenharia Agrícola, Engenheiro Civil, Arquiteto e Urbanista. Coordenador do Labore / DRH / FEC / Unicamp. Campinas [SP], Brasil. <argollo@fec.unicamp.br>.
} 


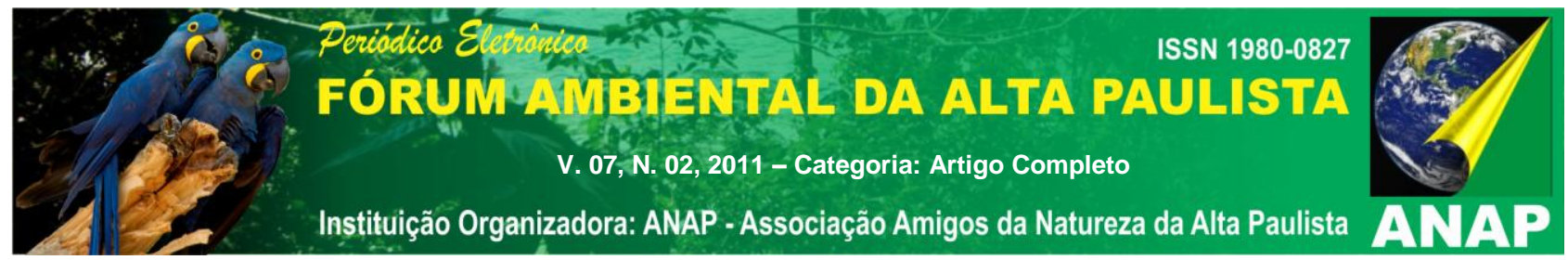

O conceito de patrimônio, em sua origem, remete às estruturas familiares, econômicas e jurídicas de uma sociedade estável, enraizada no tempo e no espaço. Todavia, com o passar do tempo, são acrescentados adjetivos como natural e cultural que, segundo Choay (2001, p.11), caracterizaram um conceito "nômade", seguindo hoje uma trajetória distinta, que se apresenta sucintamente, a seguir.

As raízes das discussões sobre patrimônio encontram-se em Roma, por volta de 1420, tendo em vista o conceito de monumento histórico, na época do Renascimento, marcado pela generalização dos ideais humanistas. Entretanto, foram as condições criadas pela Revolução Francesa que estimularam a necessidade de proteção legal. Uma das conseqüências da revolução foi o confisco de bens da Igreja, da Coroa e da aristocracia, que passaram para o domínio do Estado. Criou-se na França, em 1837, a primeira Comissão dos Monumentos Históricos. Três grandes categorias de monumentos históricos foram constituídas: os remanescentes da Antiguidade, os edifícios religiosos da Idade Média, e alguns castelos.

Segundo Scifoni (2003), ao término da Primeira Guerra Mundial as discussões sobre preservação e valorização do patrimônio estenderam-se para os demais países europeus, num primeiro esforço internacional, ainda que restrito ao velho continente. O número dos bens inventariados decuplicara, mas sua natureza era praticamente a mesma.

A essência da arqueologia, da história e da arquitetura erudita passa para todas as formas da arte de construir, clássicas e populares; urbanas e rurais; edifícios públicos e privados. O domínio patrimonial não se limita individualmente a um único edifício, mas compreende conjuntos de edificações e de cidades, como mostra a lista do patrimônio mundial estabelecida pela Unesco (Choay, 2001 p.13).

Os países europeus arrasados pelo confronto e preocupados em restaurar seu legado cultural, organizaram em 1931 uma conferência que resultou na Carta de Atenas, o primeiro documento internacional relativo a políticas de preservação do patrimônio tornando-se, por vários anos, uma referência para a restauração de bens 
culturais. A Carta de Atenas também acenava, ainda que de forma incipiente, para a inclusão do patrimônio natural. Estabelecia que, para a valorização dos monumentos, era necessário o estudo das "plantações e ornamentações vegetais convenientes a determinados conjuntos de monumentos" (IPHAN, 1995 apud SCIFONI, 2003).

No Brasil, as políticas de preservação do patrimônio têm início com 0 decreto-lei $n^{\circ} 25$ de 30 de novembro de 1937, conforme citação a seguir:

"Constitui o patrimônio histórico e artístico nacional o conjunto dos bens móveis e imóveis existentes no país e cuja conservação seja de interesse público, quer por sua vinculação a fatos memoráveis da história do Brasil, quer por seu excepcional valor arqueológico ou etnográfico, bibliográfico ou artístico" (BRASIL, 1937).

O patrimônio natural, neste estudo, é visto como o geológico, ou seja, o conjunto de formações rochosas naturais de importância reconhecida em um determinado lugar, região, ou mesmo internacionalmente. Isto é o que aponta Aziz Ab' Saber (2003) que destaca o canyon do Tietê entre Cabreúva e Itu (SP), onde o rio Tietê escavou um profundo canalão na borda ocidental das serranias paulistas de Jundiaí - São Roque, em áreas de clima "tropical de planalto". É o que ele chama de paisagens de exceção e canyons brasileiros.

Sua proteção e preservação passaram por um processo de tombamento devido ao seu reconhecimento nacional e internacional. Este artigo tem a finalidade de tratar do conceito de patrimônio e sua qualificação de "natural geológico" enfocando alguns exemplos contidos na bacia do Médio Tietê-Sorocaba, identificando sua lógica a partir de um eixo formado por um rio. Esta conexão apontará a elaboração de uma carta base para um parque fluvial geológico.

\section{CONSIDERAÇÕES SOBRE A IDÉIA DE PATRIMÔNIO NATURAL}

O "patrimônio natural" refere-se à natureza, ou à ecologia, vista como ciência que compreende a interação entre os seres vivos e os fenômenos naturais. O termo 


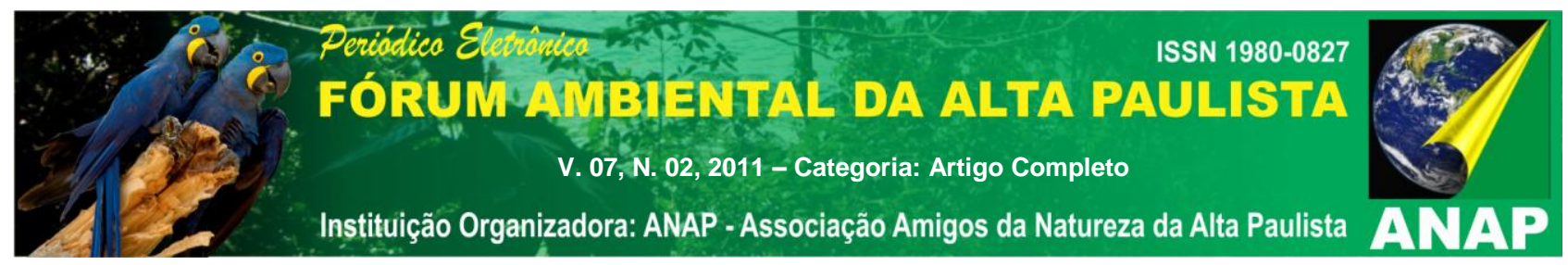

"natural" também pode ser entendido como tudo o que não possui intervenção antrópica.

O termo "patrimônio natural" pode ser encontrado como referência na legislação de alguns países europeus já na década de 1930, em que se percebe a crescente preocupação com a história natural e com os aspectos paisagísticos (estética ou beleza cênica). Na França (Lei de 02/05/1930) estabelecia-se como de interesse público a proteção de monumentos naturais e sítios de caráter científico (habitat de fauna rara, uma jazida mineral, uma estrutura geológica relevante, uma morfologia particular da terra). Na legislação italiana (Lei 1.497 de 29/06/1939) aponta-se como de interesse público os sítios de beleza natural ou de singularidade geológica e, até mesmo, uma vista panorâmica, bem como o lugar de onde se possa avistá-la, como um belveder (SCIFONI, 2003).

Dentro desse contexto é relevante destacar as características normativas do conceito de patrimônio natural. Segundo a legislação brasileira, de âmbito federal, sobre o tema - Decreto Lei 25 de 19373 - é composto por "monumentos naturais", bem como por "sítios e paisagens" cuja conservação seja necessária em decorrência da "feição notável" com que tenham sido dotados pela natureza ou agenciados pelo homem. Já do ponto de vista internacional entende-se patrimônio natural associado às noções de monumento, espécimes naturais e sítios que detenham valor universal, considerando aspectos estéticos, científicos, da conservação ou da beleza natural.

Patrimônio natural será, então, tudo aquilo que, na natureza, é monumental, possui feição notável - quer decorra da natureza ou da ação humana - tem valor universal, é belo, proporciona prazer estético, é de importância científica, é raro ou

\footnotetext{
3 O conceito de patrimônio natural mudou pouco na legislação brasileira. Segundo o Decreto ํo 80.978 de 12/12/77, o termo abrange os monumentos naturais (constituídos por formações físicas e biológicas ou por grupos de tais formações, que tenham valor universal excepcional do ponto de vista estético ou científico), as formações geológicas e fisiográficas e as áreas nitidamente delimitadas que possuam espécies animais e vegetais ameaçadas e que tenham valor universal excepcional do ponto de vista da ciência, da conservação e ainda lugares notáveis naturais ou zonas naturais que também sejam excepcionais do ponto de vista da ciência, da conservação bem como da beleza natural. (http://www.cultura.gov.br/legislacao/decretos/index.php. (Em 01/04/2011)
} 


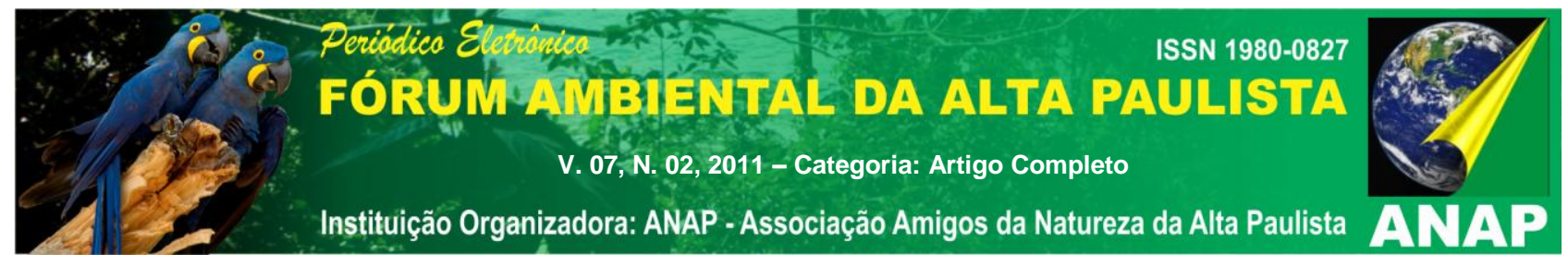

ameaçado, que refere à representação de identidade e, por fim, que deve ser protegido para as gerações vindouras. (COORDENADORIA, 2010).

Portanto, para o caso de patrimônio natural a área a ser reconhecida como de valor universal (patrimônio mundial) deve corresponder a pelo menos um dos seguintes critérios:

- Estético: paisagens notáveis e de excepcional beleza ou numa condição de paisagem de exceção. Exemplo: Jardim Botânico de Pádua, na Itália.

- Ecológico: Sítios correspondendo a habitat de espécies em risco ou que contenham processos ecológicos e biológicos importantes. Exemplo: remanescentes da Mata Atlântica.

- Científico: áreas que contenham formações ou fenômenos naturais relevantes para o conhecimento científico da história natural do planeta. Exemplo: vulcão, geleiras. (SCIFONI, 2003).

Cabe lembrar que os locais considerados patrimônio natural são áreas consideradas excepcionais do ponto de vista da diversidade biológica e da paisagem. A Unesco nomeia estas áreas como Sítios do Patrimônio Mundial Natural onde a proteção ao ambiente, o respeito à diversidade cultural e às populações tradicionais são objeto de atenção especial. Os Sítios geram, além de benefícios à natureza, uma importante fonte de renda oriunda do desenvolvimento do ecoturismo ${ }^{4}$. Desse modo fica fácil comprovar a intrínseca relação que há entre patrimônio natural e desenvolvimento regional sustentável.

\section{O PATRIMÔNIO NATURAL GEOLÓGICO: PARQUES EXISTENTES NA BACIA DO MÉDIO TIETÊ-SOROCABA.}

\footnotetext{
${ }^{4}$ Disponível em:

http://www.unesco.org.br/areas/ciencias/areastematicas/patrimonionatural/index html/mostra docume nto
} 


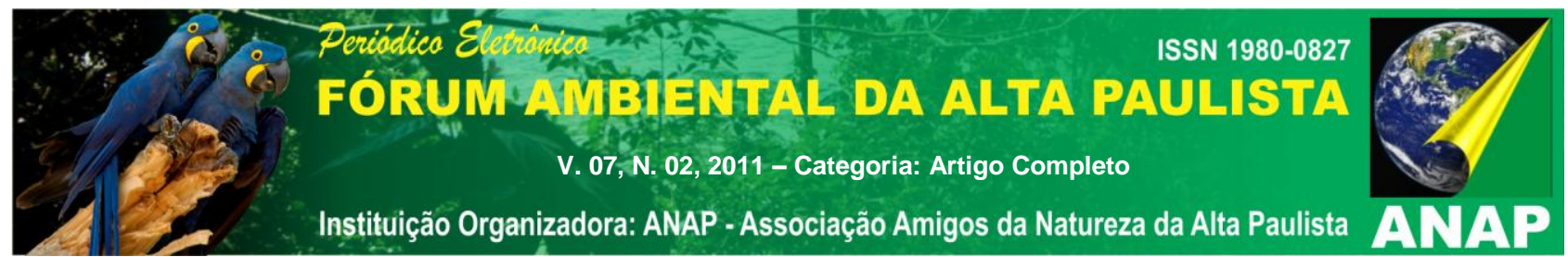

A área estudada neste artigo pertence à Bacia Hidrográfica do Sorocaba e Médio Tietê (BHSMT), território que abrange uma área de 12.099 km2 em 34 municípios do Estado de São Paulo. O rio Tietê tem cerca de 1.100 km de extensão, nasce no município de Salesópolis, na Serra do Mar. Corre para o interior em direção contrária à do Oceano Atlântico, lançando suas águas no rio Paraná, em Itapura, nas proximidades da divisa do estado de Mato Grosso do Sul. Obras hidráulicas e construções de barragens ligaram os $400 \mathrm{~km}$ de trechos navegáveis do Tietê aos 600 km navegáveis do alto do rio Paraná, criando a hidrovia Tietê-Paraná (Atlas Sócio Ambiental 2009).

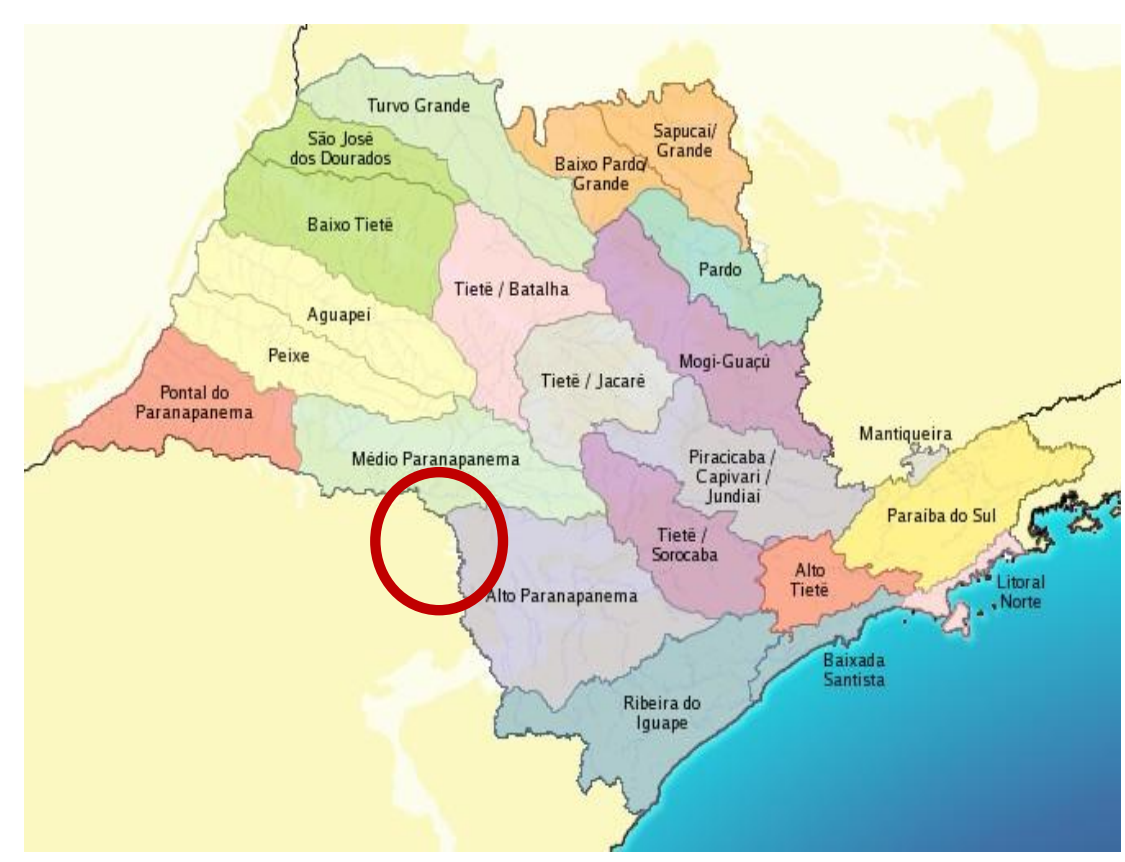

Figura 1: Bacias Hidrográficas do estado de São Paulo.

Fonte: http://mapas.znc.com.br/sos_bacias_sp/imagens/mapa_inicial.jpg

A BHSMT em toda a sua extensão constitui diversas paisagens ricas, tanto em recursos naturais como nos aspectos culturais, produzidos pelo homem no decorrer de sua trajetória. Estes valores da Natureza e Cultura refletem a história da agricultura na região, o patrimônio da indústria, do povoamento e da expansão do território paulista. Constituem registros na paisagem dos processos sociais e econômicos, imateriais ou edificados, atributos de uma significativa parcela da 
população brasileira, que estabelece assim sua narrativa. Não se trata de uma situação estática, mas da construção e do desenvolvimento de sua sociedade e de sua cultura. Com base neste contexto a bacia hidrográfica aparece como relevante objeto de estudo visando na compreensão de como seus recursos patrimoniais naturais e culturais- são constituídos no transcorrer do tempo.

Tendo em vista o recorte espacial tomado para este estudo, a área a ser analisada possui quatro parques já constituídos: Estrada Parque APA Cabreúva-Itu; Parque dos Varvitos em Itu; Parque Rocha Moutonée em Salto e Parque das Monções em Porto Feliz. Além destes parques -já edificados- existe a possibilidade de criação de mais um parque na região, o Parque dos Matacões, entre os municípios de Salto e Itu. Para além do caráter histórico da região, os parques contam com diversidade de natureza, ricos -tanto em fauna e flora, como em vestígios geológicos- o que será ressaltado na proposta de um parque fluvial geológico, a partir das reflexões explicitadas neste estudo.

Ab'Sáber(2003) caracterizou o canyon do Tietê à jusante de Cabreúva e à montante de Itu como um importante desfiladeiro, internamente revestido por uma densa floresta tropical biodiversa. A novidade reside no fato que nas poucas vertentes onde afloram matacões ou lajes de granito existem remanescentes minirrelictos de mandacarus, indicando que cactáceas precederam as florestas tropicais da região.

No campo do patrimônio natural há que se considerar a identificação destes elementos ressaltados por Carpi Jr. (2010) como formas de percepção do território que valorizam o geopatrimônio regional através dos seguintes elementos naturais do Vale do Médio Tietê:

- A zona de contato entre o Planalto Atlântico e a Depressão Periférica.

- O rio Tietê.

- Os canyons dos rios Tietê e do rio Piraí.

- Os matacões de granito.

- As áreas de mata nativa e os vestígios de caatinga. 


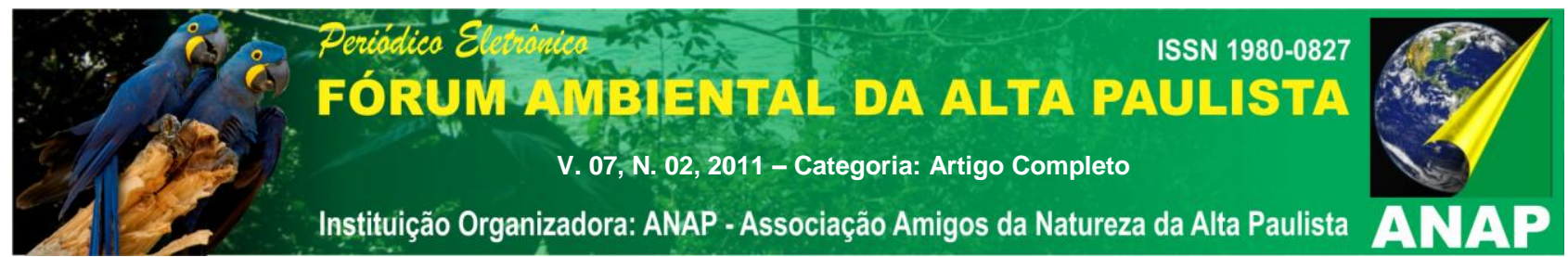

O destaque, segundo o autor, também fica por conta do canyon, como patrimônio natural fundamental. Além do conjunto de elementos de interesse ambiental, formado pelos matacões, morros, grutas, cobertura vegetal variada, há também os conjuntos de interesse histórico como as fazendas e cidades. Assim a extensão do canyon ao longo do rio Tietê e a porção do território entre os municípios de Cabreúva e Porto Feliz, -local em que se concentram os elementos do patrimônio natural geológico- destacam-se os seguintes aspectos:

- A forma geográfica de o rio percorrer este trecho encaixado em um canyon, área de grande beleza cênica.

- Área que ainda sofre os efeitos da poluição, mas apesar disto, mantém seu valor paisagístico.

- Diversidade de fauna e flora de Mata Atlântica e Caatinga. A região estudada pertence a uma área de APA (área de proteção ambiental).

- Potencial turístico evidenciado pelas fazendas, campings, parques, patrimônio industrial como a Usina Hidrelétrica São Pedro e manifestações culturais como romarias e cavalgadas.

- Cidades que já são estâncias turísticas como Salto e Itu e outras que têm a potencialidade de serem reconhecidas como tal, principalmente pelo rico patrimônio arquitetônico e cultural da região, como são os casos de Cabreúva e Porto Feliz.

As áreas mais significativas no que se refere ao patrimônio natural da região, já evidenciadas anteriormente por diversos pesquisadores, são devidamente reconhecidas pelas cidades a que pertencem. Pode-se, portanto, estabelecer-se uma carta de percurso, dentro da lógica das individualidades dos parques, e dentro de seu conjunto, simulando-se um experimento projetual consubstanciado num parque fluvial a partir da valorização do patrimônio natural geológico.

\section{O CANYON (ESTRADA PARQUE CABREÚVA - ITU).}


É muito difícil separar as cidades que compõem o universo deste estudo, do rio Tietê. Em suas respectivas histórias o rio representa importante papel desde a época das bandeiras até os nossos dias, refletindo-se na própria história paulista. $O$ canyon apresenta a sinuosidade própria do leito do rio, que tem corredeiras por entre os matacões. O trecho do rio entre as cidades de Cabreúva e Itu possui grandes atrativos cênicos, pois é encaixado a mais de 200 metros com encostas cobertas por densa mata tropical latifoliada, além de uma gruta natural também formada pelos matacões. (TOSCANO, 1977).

\section{OS MATACÕES}

A região entre Itu e Salto (incluindo seu entorno) apresenta um dos mais importantes sítios fitogeográficos e geoecológicos do Brasil, conforme nos ensina Ab' Saber (2003). Este espaço se constitui de cobertura vegetal de cerrado, cactáceas e matas de fundo de vale e encostas baixas. Os componentes fitogeográficos e litológicos constituem vínculos de vegetação e rochas, formando paisagens locais bem diversas.

As mencionadas áreas já sofreram intervenção antrópica, pois vêm sendo ocupadas por indústrias, olarias e lavras de granito, em diferentes épocas. Atualmente encontram-se ainda mais afetadas pela duplicação da rodovia Dom Gabriel Bueno Couto. Não existe a configuração de um parque, mas sua propositura já foi apontada em estudos anteriores na região.

Uma das mais recentes descobertas de interesse científico e de caráter internacional na área dos Matacões é a Gruta do Riacho Subterrâneo em Itu. Nesta caverna há uma grande variedade de espeleotemas, diversidade de fauna, fragmento de um artefato cerâmico (ainda não datado), que evidencia a Gruta do Riacho Subterrâneo não apenas pelo seu notável desenvolvimento ou pela sua litologia, mas também por esses diversos atributos. Tais características despertaram interesse em outros especialistas, que já iniciaram outros trabalhos nas áreas de 
arqueologia, biologia e mineralogia, envolvendo até o momento 49 pessoas nas atividades de campo das Universidades USP e UFSCar. Isto é destacado pelo boletim eletrônico TETO BAIXO (2011). De acordo com os Cadastros Brasileiros de Cavernas e rankings mundiais de desenvolvimentos, hoje se pode afirmar que a Gruta do Riacho Subterrâneo ocupa a primeira posição do Brasil, América do Sul e Hemisfério Sul e já se encontra entre as seis maiores cavernas em granito do mundo, com possibilidades de se aproximar das primeiras posições.

\section{O PARQUE DO VARVITO.}

A Pedreira de Varvito de Itu é uma ocorrência da geologia com reconhecimento nacional e internacional. Prova disto são os diversos estudos e pesquisas científicas realizados em diferentes países, que a apontam como a mais importante ocorrência desta rocha em toda a América do Sul. Juntamente com outras rochas como a "pedra moutonée", e os "tilitos" (conglomerados glaciais), constituem importantes evidências da ocorrência de clima frio ou glacial na região, tendo em vista que tais rochas foram formadas pela ação das geleiras, ao longo de períodos geológicos que afetaram a Terra nas Eras Pré-Cambriana e Paleozóica.

O Parque do Varvito foi criado a fim de proteger e dar visibilidade à grande importância desta pedreira como documento-monumento da história geológica do Brasil. O reconhecimento da laje de Itu como varvito, em 1938, deve-se a Othon H. Leonardos, geólogo do então Serviço de Fomento da Produção Mineral do Brasil. Ele considerou a pedreira como a "mais linda exposição de varvitos encontrada no país". A partir daquele ano, o local tornou-se geologicamente famoso e, desde então vem sendo frequentemente visitado por geólogos, cientistas, professores e estudantes do Brasil e do exterior, todos interessados em examinar esta excepcional e rara exposição de rocha peculiar.

A transformação da Pedreira de Varvito em Parque Municipal teve o objetivo de preservar este patrimônio, assim como oferecer atividades de lazer e cultura. $\mathrm{O}$ 


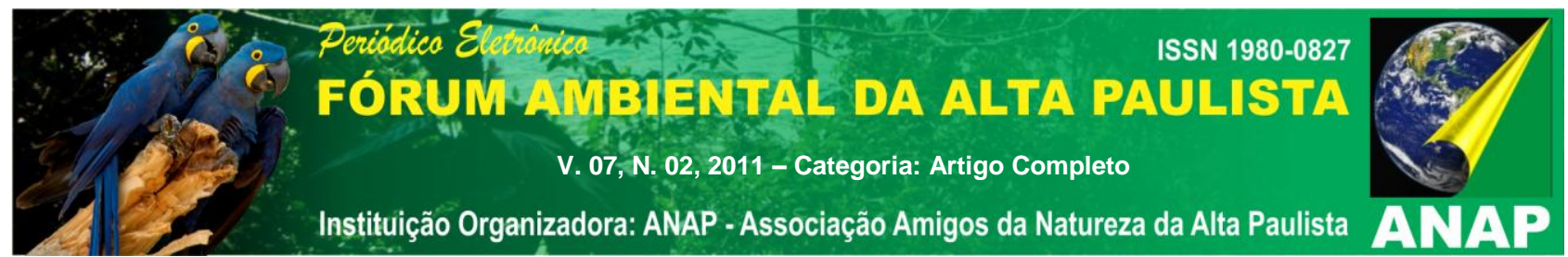

monumento geológico foi tombado em 1974, pelo Condephaat (Conselho de Defesa do Patrimônio Histórico, Arqueológico e Artístico do Estado de São Paulo) e possui área de $44.346 \mathrm{~m}^{2}$, segundo dados da Prefeitura da Estância Turística de Itu.

\section{O PARQUE ROCHA MOUTONÉE}

A rocha Moutonée é um granito róseo de idade estimada, cientificamente, em 250 milhões de anos. O nome Moutonée é atribuído ao tipo de rocha de formato arredondado, que lembra um carneiro deitado (mouton no francês, significa carneiro; moutonée: acarneirada). Cientistas e pesquisadores comprovaram o fenômeno da glaciação na era Paleozóica, ocorrido há 270 milhões de anos, responsável pelas rachaduras e estrias na superfície da rocha, que foi descoberta em 1946, pelo geólogo Marger Gutmans do Instituto Agronômico de Campinas e tombada pelo Condephaat.

O Parque Rocha Moutonée, com $43.338 \mathrm{~m}^{2}$ de área, é considerado pela Prefeitura Municipal de Salto como o primeiro parque ecológico e geo-histórico do continente, segundo informações de seu folder turístico. Às margens do rio Tietê conta com estrutura para estudos e lazer. Este sítio foi antiga fazenda (Bicudo), pedreira que explorava pedras desde os anos 1950, usadas para calçamento e outros materiais. Isto quase destruiu inteiramente a rocha Moutonée. A parte preservada, entretanto, é suficiente para mostrar as principais características desse importante testemunho geológico da idade glacial de Gondvana (super continente que era formada a Terra na época glacial neopaleozóica).

\section{O PAREDÃO ROCHOSO (PARQUE DAS MONÇÕES EM PORTO FELIZ).}

Inicialmente ao "paredão" foi dado o nome de Araritaguaba, termo de origem indígena (arara + ita +guaba = arara + pedra + comer). O nome dado à localidade porque havia na margem esquerda do então rio Anhembi (Tietê) árvores frondosas e 


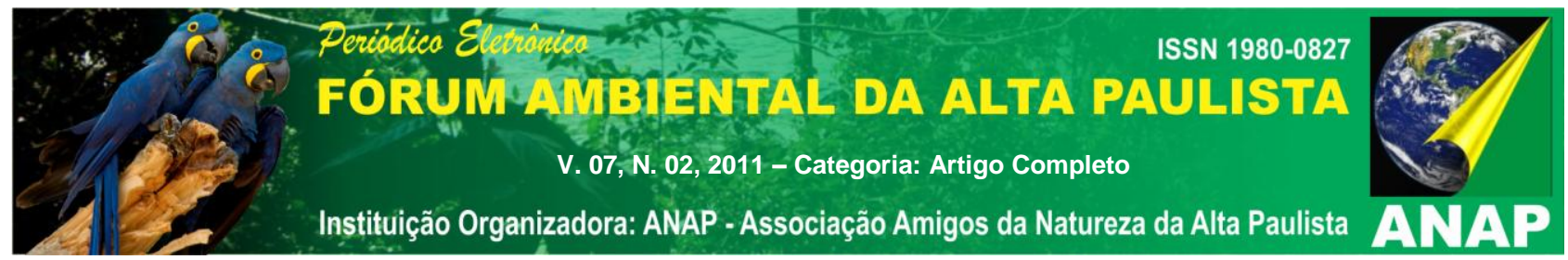

floridas que descansavam à sombra de um alto paredão, onde as araras bicavam suas areias salitrosas em busca de alimento.

Formado por calcário, arenito e rocha sedimentar esburacada, o paredão salitroso de rocha sedimentar intriga ainda hoje os geólogos. Acredita-se que o paredão possa provar que, há milhões de anos, o local teria sido o fundo do mar ou as margens de um grande lago no período glacial. Tem aproximadamente trinta metros de altura ladeia o passeio do parque conduzindo até uma gruta erigida em louvor a Nossa Senhora de Lourdes, réplica da existente no sul da França, construída por dois padres franceses: Alexandre Hordeau e Vitor Marai Cavron. Hoje este paredão faz parte do Parque das Monções e chama a atenção pelas suas formas e cores.

\section{ELABORAÇÃO DA CARTA BASE PARA O PARQUE FLUVIAL GEOLÓGICO CABREÚVA, ITU, SALTO E PORTO FELIZ.}

A partir do reconhecimento do importante patrimônio natural geológico da região, tendo em vista os parques existentes e o correspondente potencial de se transformarem em novas áreas de estudos e lazer, procurou-se elaborar uma carta, destacando-se as cidades da região e enfatizando o rio Tietê como o condutor de percurso de um parque fluvial que venha adicionar-se aos outros parques em seu contexto. Também se utilizou do recurso fotográfico para ilustrar a carta base proposta.

O percurso compõe-se de um conjunto de monumentos geológicos naturais, rochas de valor inestimável para se contar a história do planeta. A localização destes patrimônios ao longo do rio determinou a lógica de um parque fluvial geológico. Esta é carta base proposta para este parque: 

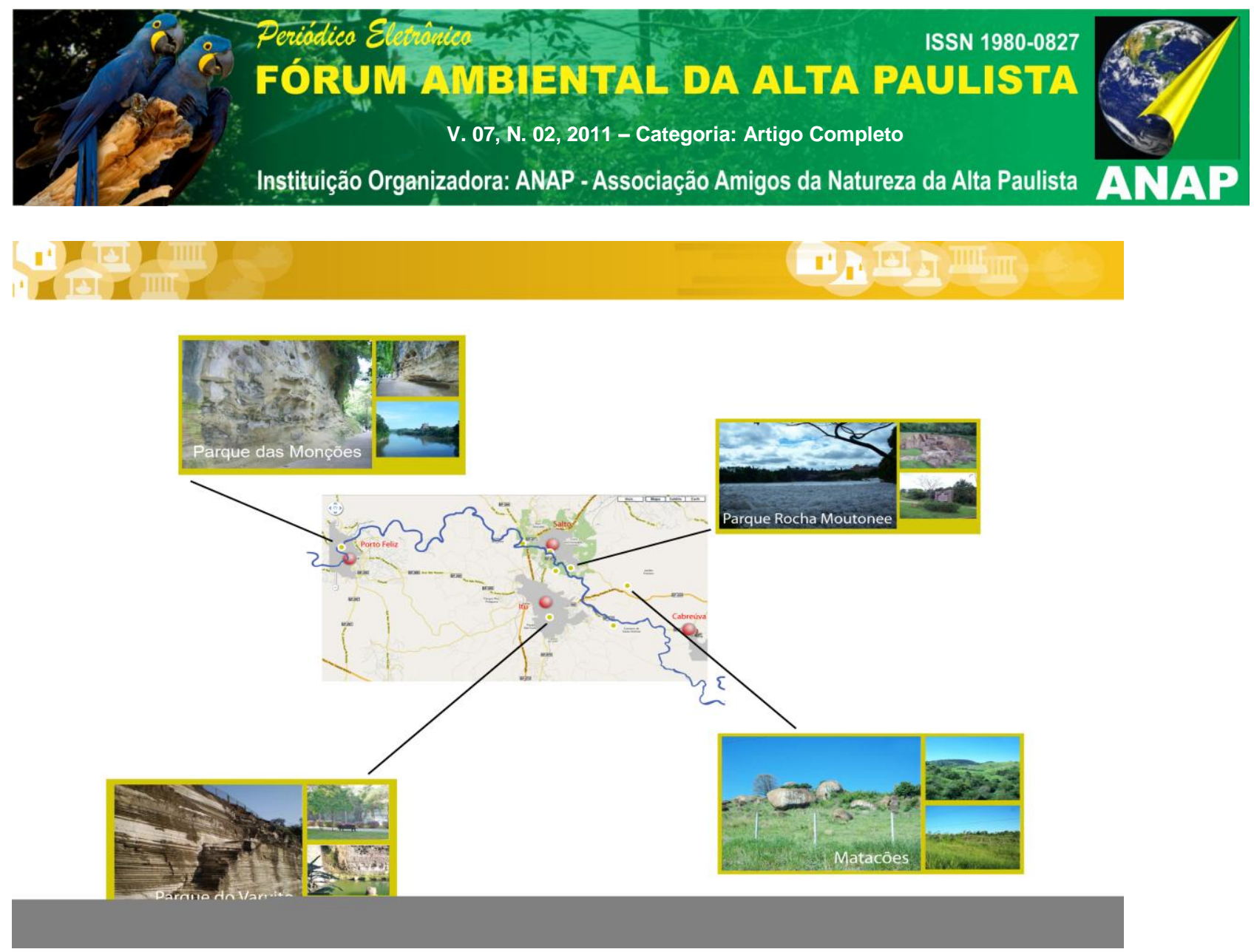

Figura 2. Carta de percurso proposta pelo autor

\section{A EXPERIÊNCIA INTERNACIONAL: O VALE DO RIO LLOBREGAT, ESPANHA.}

O rio pensado em seu conjunto e pela composição de seus diversos parques já foi um desafio elaborado por Sabaté et al. (2001) pela visão da UPC (Universidade Politécnica da Catalunha) e MIT (Massachusetts Institute of Technology) como ordenamento territorial e desenvolvimento regional, que foi desenvolvida durante pesquisa destas Universidades na região da Catalunha, Espanha. Este modelo de parque fluvial já proposto no rio Llobregat trouxe um novo sentido e novas atividades para cada parte do rio. Durante o estudo o grupo constatou:

- Uma bacia hidrográfica mais apreciável, com locais educacionais para se conviver, aprender e observar a diversidade geológica, além de outras, ao longo do rio. 
- Uma rede de locais especializados que interpretem o local e museus que podem incluir centros de visitação e orientação temáticos, com localizações estratégicas, e cidades importantes da bacia. Eles podem todos juntos narrar a história do rio Llobregat bem como promover o que há para se ver na região. Eles podem desempenhar um papel de educação como local de aprendizagem das escolas, promovendo espaços, encontros, aulas e apresentações da história regional e da cultura local.

- Reutilização das antigas fábricas e outros elementos arquitetônicos das colônias. Edifícios poderiam ser renovados para abrigar uma nova gama de atividades - hotéis e centros de conferência, escolas e instituições de ensino, residências para as comunidades de Barcelona, pesquisa de novas tecnologias espaços de escritórios, todos mantendo o desenho e o caráter do assentamento histórico.

- Uma rede viária revitalizada. Rede da malha viária local associada com o rio pode ser restabelecida como uma rota turística cênica, conectando a parte recreacional, educacional e os locais históricos. Isto pode ser feito a pé ou por bicicleta.

- Novas oportunidades recreativas nas montanhas. Promover turismo educacional e recreação no norte do rio e nas montanhas, promovendo cidades como Berga, que podem oferecer alojamento e entretenimento para os visitantes nessa época.

As qualidades naturais se aplicam às paisagens tanto internacionais como no Brasil, pois têm uma beleza natural intrínseca e se encontram em estado relativamente preservado. Essas qualidades são as formações geológicas, fósseis, forma do terreno, presença de cursos hídricos, vegetação e vida silvestre. Estas características naturais devem sofrer um mínimo de intervenção e uma de suas possibilidades de atividade recreativa é entender as diversas formações geológicas através de seu percurso. 


\section{CONSIDERAÇÕES FINAIS}

Pretendeu-se caracterizar o Patrimônio Natural Geológico como um componente fundamental da paisagem fluvial no Médio Tietê-Sorocaba através de conceitos e enfoques consolidados, em contraposição com outros complementares, de maneira a evidenciá-los na forma de uma proposta projetual de um parque fluvial, formado pela união dos parques existentes na região.

O imenso patrimônio geológico possui relevância intrínseca tanto no contexto nacional como internacional. O patrimônio natural geológico do Médio Tietê-Sorocaba deve ser preservado, tendo em vista seu reconhecido valor inerente. As políticas de preservação de sua paisagem devem reconhecer sua história e, portanto, seu imenso valor cultural.

Este importante patrimônio natural além de merecer a preservação de seus recursos naturais e biodiversidade, permite resgatar algumas áreas do ostracismo em que se encontra, seja submetendo-as a um produto de consumo com o invólucro de parques que pode contribuir para melhoria das localidades mais diretamente envolvidas no processo, seja como uma área distinta para estudos científicos, educação ambiental e patrimonial, cultura e lazer. Este modelo assume o caráter de preservação científica e, portanto, ambientalmente correta por meio de sua leitura e percurso através do rio, ou seja, compondo o que chamamos de um parque fluvial.

Tal modelo já é usado em outros países, como a Espanha, que se utiliza da elaboração em seu planejamento territorial dos parques como forma de requalificação urbana e regional. Este artigo permite visualizar a aplicação do conceito de parque fluvial como requisito para compor uma síntese dos conceitos de patrimônio natural de uma determinada região. O rio, neste caso, é o elemento que aglutina e integra o recurso natural geológico e o cultural. Sob este ponto de vista, o patrimônio da bacia hidrográfica do Médio Tietê-Sorocaba constitui-se como importante fonte de pesquisas, para além do seu caráter turístico propriamente dito, assumindo funções pedagógicas, científicas, turísticas e culturais. O parque fluvial pode contribuir para a preservação e manutenção deste rico patrimônio, pois sua 


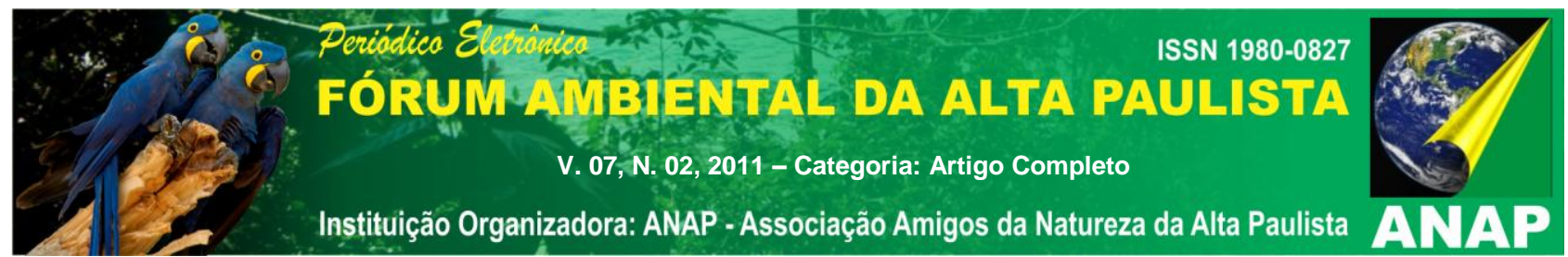

leitura em forma de percurso propicia a compreensão do território sob o ponto de vista natural, social cultural e estético.

\section{REFERÊNCIAS}

AB' SÁBER, Aziz Nacib. Os domínios da natureza no Brasil: potencialidades paisagísticas. São Paulo: Ateliê Editorial. 2003.

BRASIL. Decreto-lei $n^{\circ} 25$ de 30 de novembro de 1937. Organiza a Proteção do Patrimônio Histórico e Artístico Nacional. Disponível em: http://www.antt.gov.br/legislacao/Regulacao/suerg/Dec-lei2537.pdfhttp://www.antt.gov.br/legislacao/Regulacao/suerg/Dec-lei25-37.pdf. Acesso em: 17 ago. 2011.

CARPI JÚNIOR, S. Unidades Geoambientais patrimônio natural no Vale do Médio Tietê, SP, Brasil. In: SEMINÁRIO LATINO AMERICANO DE GEOGRAFIA FÍSICA, 6. , 2010.

CHOAY, Françoise. Alegoria do patrimônio. São Paulo: Editora Unesp, 2001

COORDENADORIA do Patrimônio Cultural do Estado do Paraná. Desenvolvido pela Secretaria de cultura do Paraná, 2010. Disponível em: http://patrimoniocultural.pr.gov.br. Acesso em 17/08/2011.

DECRETO n 80.978, de 12.12.77 - Promulga a Convenção Relativa a Proteção do Patrimônio Mundial, Cultural e Natural, de 1972, disponível em:

http://www.cultura.gov.br/legislacao/decretos/index.php?p=54\&more $=1 \& \mathrm{c}=1 \& \mathrm{tb}=1 \& \mathrm{pb}=1$.

Acesso em 23/04/07.

FONSECA, Maria Cecília Londres. O Patrimônio em Processo. Rio de Janeiro: Editora UFRJ, 2005.

GARCIA, José Geraldo: Parque do Varvito, Itu-SP José Geraldo Garcia; [ texto de ] Jonas Soares de Souza; [ consultoria de] Antonio Carlos Rocha Campos. 1998.

GOMES CARNEIRO, Celso Fernando de Azambuja. Patrimônio Natural e valores, Secretaria de Estado da Cultura do Paraná - Coordenadoria do Patrimônio Cultural, disponível em http://www.patrimoniocultural.pr.gov.br/. Acesso em 16/04/2007

LEMOS, Carlos A. C. O que é patrimônio Histórico?. São Paulo: Editora Brasiliense, 1987.

MODENESI, May Christine. Contribuição a geomorfologia da região de Itu - Salto. Dissertação (Mestrado), GEOUSP 2008.

PARQUE Rocha Moutonée. Salto: Prefeitura Municipal, SP, 1991.

SABATÉ, J. et al. Projectant l' eix del Llobregat. Paisage cultural i desenvolupament regional. Barcelona: UPC, 2001.

SANTOS, José Luiz dos. O que é cultura? São Paulo: Brasiliense, 2004. 16.ed.

SCIFONI, S. Patrimônio mundial: do ideal humanista à utopia de uma nova civilização.

Geousp, São Paulo, v. 14, p. 77-88, 2004, disponível em: 


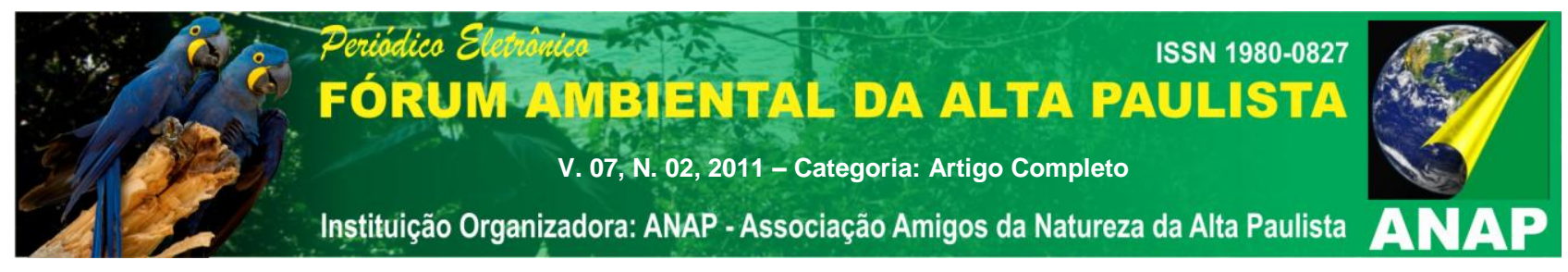

http://www.geografia.fflch.usp.br/publicacoes/Geousp/Geousp14/Geousp_14_Scifoni.htm. Acesso em 20/04/07

SILVA, Fernando Fernandes da. As cidades brasileiras e o Patrimônio Cultural da Humanidade. São Paulo: Edusp: Petrópolis, 2003.

SITIO Ecológico da Rocha Moutonée. Salto, SP: Prefeitura, 1990.

TETO BAIXO. Ano II número 2. Boletim Eletrônico do GPME. Grupo Pierre Martin de Espeleologia. 05/05/2011.

TOSCANO, João Walter. Diagnóstico Geral da Cidade de Itu para a implementação de um programa de ação cultural. São Paulo: CONDEPHAAT, 1977.

UNESCO. Patrimônio Natural. Disponível em http://www.unesco.org.br/areas/ciencias/areastematicas/patrimonionatural/index_html/mostr a_documento. Acesso em: 10/04/07. 